NBER WORKING PAPER SERIES

\title{
IS THE ELDEST SON DIFFERENT? THE RESIDENTIAL CHOICE OF SIBLINGS IN JAPAN
}

Midori Wakabayashi

Charles Y. Horioka

Working Paper 12655

http://www.nber.org/papers/w12655

\author{
NATIONAL BUREAU OF ECONOMIC RESEARCH \\ 1050 Massachusetts Avenue \\ Cambridge, MA 02138 \\ October 2006
}

We would also like to thank Editor-in-Chief Robert Dekle, an Associate Editor, and an anonymous referee of this Journal, Naohito Abe, Shigeki Kano, Daiji Kawaguchi, Kouhei Kubota, Wataru Kureishi, Oleksandr Movshuk, Shizuka Sekita, Kwanho Shin, Keiko Tamada, the members of Horioka's graduate seminar, and seminar participants at Toyama University and Osaka Prefecture University for their helpful comments and discussions. We also thank National Family Research of Japan and the Information Center for Social Science Research on Japan, Institute of Social Science, University of Tokyo (SSJ Data Archive) for providing micro data from the 1998 National Survey of Families (Kazoku ni tsuiteno Zenkoku Chousa) (SSJDA0191) and the Ministry of Education, Culture, Sports, Science and Technology of the Japanese Government for Grants-in-Aid for Scientific Research numbers 18330068, 19330062, and 20223004 and the Global Center of Excellence (GCOE) Project of the Graduate School of Economics and the Institute of Social and Economic Research of Osaka University, which supported this research. The views expressed herein are those of the author(s) and do not necessarily reflect the views of the National Bureau of Economic Research.

(C) 2006 by Midori Wakabayashi and Charles Y. Horioka. All rights reserved. Short sections of text, not to exceed two paragraphs, may be quoted without explicit permission provided that full credit, including $(\odot$ notice, is given to the source. 
Is the Eldest Son Different? The Residential Choice of Siblings in Japan

Midori Wakabayashi and Charles Y. Horioka

NBER Working Paper No. 12655

October 2006, Revised December 2009

JEL No. D12,D91,J14,Z13

\begin{abstract}
$\underline{\text { ABSTRACT }}$
In this paper, we analyze the determinants of the living arrangements (coresidence behavior) of elderly parents and their children (whether elderly parents live with their children, and if so, with which child) in Japan using micro data from a household survey. Our results provide support for all four explanations of coresidence behavior but especially for the life cycle and dynasty models (both of which assume selfishly motivated parents) and social norms and traditions: The fact that parents who were self-employed before retirement are more likely to live with their children, the fact that parents are less likely to live with sons who adopt their wife's surname, and the fact that parents are more likely to live with daughters whose husbands adopt their surname constitute evidence in favor of the dynasty model. The fact that parents who were (relatively wealthy) executives before retirement and parents who are homeowners are more likely to live with their children and the fact that parents are more likely to live with less educated children constitute evidence in favor of the selfish life cycle model (or the altruism model). And the fact that parental attitudes toward their children affect their coresidence behavior, the fact that parents are more likely to live with their eldest child if their eldest child is a son, and the fact that parents are most likely to live with their eldest son even if he is not the eldest child constitute evidence in favor of social norms and traditions.
\end{abstract}

Midori Wakabayashi

College of Economics

Osaka Prefecture University

1-1, Gakuen-cho

Sakai, Osaka 599-8531 JAPAN

mwaka@eco.osakafu-u.ac.jp

Charles Y. Horioka

Institute of Social and Economic Research

Osaka University

6-1 Mihogaoka, Ibaraki-shi

Osaka-fu 567-0047 JAPAN

and NBER

horioka@iser.osaka-u.ac.jp 


\section{Introduction}

Children, especially eldest sons, are much more likely to live with their elderly parents in Japan than in the West. Why is that? What motivates elderly parents and their children to live with each other in Japan? Which child tends to live with the parents in Japan and why? Is it possible to explain the living arrangements (coresidence behavior) of elderly parents and their children in Japan using existing theoretical models of household behavior or do we have to resort to social norms and traditions? The social norm in Japan has been for the eldest son to live with his elderly parents, to take care of them, to carry on the family line, and to receive the parents' entire bequest including the family home, and it is possible that the eldest son lives with his elderly parents not because it is economically rational for him to do so but simply because he is adhering to the aforementioned social norm.

In this paper, we analyze the determinants of the living arrangements (coresidence behavior) of elderly parents and their children (whether elderly parents live with their children, and if so, with which child) in Japan using micro data from the 1998 "National Family Survey (in Japanese, Kazoku ni tsuiteno Zenkoku Chousa)," which was conducted in January 1999 and provided by National Family Research of Japan and the Information Center for Social Science Research on Japan, Institute of Social Science, University of Tokyo (SSJ Data Archive). In so doing, we try to shed light on which theoretical model of household behavior (the dynasty model, the selfish life cycle model, or the altruism model) applies in Japan and the extent to which Japanese households adhere to social norms and traditions.

There have been a number of studies of the determinants of the living arrangements of elderly parents and their children in Japan. One such study is Horioka, et al. (2000), which analyzes data from the 1996 "U.S.-Japan Comparison Survey of Saving (Chochiku ni kansuru Nichibei Hikaku Chousa)," conducted by the Institute of Posts and Telecommunications Policy of the former Ministry of Posts and Telecommunications of the Government of Japan, and finds that elderly parents are more likely to live with their children if they are planning to leave a bequest to their children, whereas such a relationship is not observed in the United States. Similarly, Ohtake (1991) and Ohtake and Horioka (1994) analyze data from the 1986 
"National Livelihood Survey (Kokumin Seikatsu Kiso Chousa)," conducted by the Ministry of Health, Labor and Welfare of the Government of Japan, and find that the likelihood of coresidence increases as the bequeathable wealth (housing assets) of elderly parents increases. ${ }^{1} \quad$ Iwamoto and Fukui (2001) analyze data from the 1986 and 1995 administrations of the same survey used by Ohtake (1991) and Ohtake and Horioka (1994) and find that elderly parents living in the ten largest cities (the value of whose land holdings is much higher than those living in other areas) are more likely to live with their children than those living elsewhere. All of these results suggest that the Japanese are selfishly motivated, with elderly parents using bequests to induce their children to live with them, and children living with their elderly parents in order to receive a bequest from their parents.

Yamada (2006) analyzes data from the "Survey on Life Planning in the Age of Long Life (Chouju Jidai no Seikatsu Sekkei)," conducted by the Japan Institute of Life Insurance in 1992, and finds that children are more likely to live with their parents if they expect to inherit their parents' home, if both the husband and wife work, and if they have pre-nursery school age children. These results suggest that children are selfishly motivated in Japan and that they live with their parents in order to inherit their parents' home and/or in order to elicit child care services from their parents. In a related vein, Kureishi and Wakabayashi (2007) analyze data from the 2003 "National Family Survey (in Japanese, Kazoku ni tsuiteno Zenkoku Chousa)," the same data source used in this paper, and find that children's desire to live with their parents is motivated by a desire to receive child care services from their parents. All of the foregoing results imply that both parents and children are selfish in Japan and that their coresidence behavior is selfishly motivated.

By contrast, Ando, et al. (1986) find that children who are self-employed are more likely to live with their elderly parents, and Iwamoto and Fukui (2001) find that elderly parents who are farmers are more likely to live with their children. To the extent that Japanese children who live with their elderly parents are more likely to inherit and carry on the family business or the family farm, these findings suggest that the dynasty model applies to at least some extent in Japan. 
Finally, Martin and Tsuya (1991) and Tsuya and Martin (1992) find that the coresidence behavior of parents and children in Japan is determined in part by social norms, with sons living in small towns or rural areas and sons in arranged marriages (both of whom are more likely to hold traditional views), eldest sons, and daughters married to men other than eldest sons being more likely to live with their parents. However, Martin and Tsuya (1991) also find that social norms have weakened over time, with the elderly relying less on sons and daughters-in-law and more on spouses and daughters for assistance.

Thus, previous studies of the living arrangements (coresidence behavior) of elderly parents and their children in Japan suggest that the selfish life cycle model, the dynasty model, and social norms all hold in Japan to some extent and can partly explain the coresidence behavior of parents and children in Japan, but they suffer from a number of drawbacks such as their failure to take account of siblings (multiple children). ${ }^{2}$

The contributions of this paper are as follows: first, our paper is the first to analyze the living arrangements (coresidence behavior) of elderly parents and their children focusing on the number of children and the composition of children's siblings in Japan. We believe that it is important to take account of information on the number of children and on the composition of children's siblings when analyzing the living arrangements of parents and their children because many hypotheses regarding living arrangements predict that these factors will be important (for example, the dynasty model of Chu (1991) and the strategic bequest motive of Bernheim, et al. (1985)). Many previous studies, especially Japanese studies, had no choice but to ignore children who are not living with their parents because of data limitations. In this paper, by contrast, the survey we use contains various information not only on the elderly parents but also on every child, including the distance between the residence of the parents and that of every child, which will enable us to analyze the living arrangements of elderly parents and their children rigorously.

The second contribution of this paper is to analyze the impact of social norms and traditions on the living arrangements (coresidence behavior) of elderly parents and their children. The survey we use asks respondents about their attitudes towards their children, 
and since these questions capture whether or not respondents adhere to Japanese social norms and traditions, we can use them to analyze the impact of social norms and traditions on the living arrangements of parents and their children.

To preview our main findings, our results provide support for all four explanations of coresidence behavior but especially for the life cycle and dynasty models (both of which assume selfishly motivated parents) and social norms and traditions: The fact that parents who were self-employed before retirement are more likely to live with their children, the fact that parents are less likely to live with sons who adopt their wife's surname, and the fact that parents are more likely to live with daughters whose husbands adopt their surname constitute evidence in favor of the dynasty model. The fact that parents who were (relatively wealthy) executives before retirement and parents who are homeowners are more likely to live with their children and the fact that parents are more likely to live with less educated children constitute evidence in favor of the selfish life cycle model (or the altruism model). And the fact that parental attitudes toward their children affect their coresidence behavior, the fact that parents are more likely to live with their eldest child if their eldest child is a son, and the fact that parents are most likely to live with their eldest son even if he is not the eldest child constitute evidence in favor of social norms and traditions.

This paper is organized as follows: in section 2, we discuss four theoretical models of household behavior and their implications for parent-child coresidence; in section 3, we describe the data source and sample selection; in section 4, we describe the estimation model and estimation method; in section 5, we present some descriptive statistics; in section 6 , we present our estimation results; and section 7 concludes.

\section{Theoretical Considerations}

In this section, we briefly introduce four theoretical models of household behavior and discuss their implications for parent-child coresidence.

(I) The Dynasty Model. 
The dynasty or lineal model of Chu (1991) assumes that parents care about the perpetuation of the family line and/or the family business and hence that they will behave so as to minimize the probability of lineal or dynastic extinction. Thus, this model implies that parents will leave a bequest to their children only if their children carry on the family line and/or the family business. It is common for the child who carries on the family line and/or the family business to live with his or her parents, as discussed in more detail in section 4 below, so this model implies that the child who carries on the family line and/or the family business will live with the parents.

(II) The Selfish Life Cycle Model.

The selfish life cycle model of Modigliani and Brumberg (1955) assumes that parents as well as children are selfish and implies that parents will not leave a bequest to their children unless their children live with them and take care of them during old age (i.e., that they will induce their children to live with them and take care of them during old age by promising them a bequest if they do so). By the same token, children will not live with their parents and take care of them during old age unless they expect to receive a bequest from their parents (i.e., they will induce their parents to leave a bequest to them by living with them and taking care of them during old age). In short, bequests will be a quid pro quo for coresidence and care during old age and conversely. See Bernheim, Summers, and Shleifer (1985) for a rigorous theoretical analysis of this so-called "strategic bequest motive."

(III) The Altruism Model.

The altruism model of Barro (1974) and Becker $(1974,1981,1991)$ assumes that parents are altruistic (harbor intergenerational altruism) towards their children and that they derive utility not only from their own consumption but also from the consumption of their children. This model implies that parents will leave a bequest to their children whether or not their children live with them and take care of them during old age. By the same token, if children are also altruistic, they will live with their parents and take care of them during old age whether or not 
they expect to receive a bequest from them. Thus, if individuals behave according to the altruism model, there should be no relationship between coresidence and bequest motives (unless both parents and children are altruistic).

\section{(IV) Social Norms and Tradition.}

In Japan, it is customary for children (especially the eldest son) to live with their parents and to take care of them during old age even if their parents do not leave a bequest to them. This custom arises not from economic considerations but from social norms and traditions-in particular, from the Confucian teaching that, when children grow up, they should respect and take care of their parents even if their parents do not leave a bequest to them. The observed behavior - that children live with their parents and take care of them during old age even if their parents do not leave a bequest to them--is identical to the case in which children are altruistic toward their parents (see model III above), but the mechanism is totally different. See Sakudo (2007) for a theoretical (Nash bargaining) model of parent-child coresidence that incorporates such a social norm or tradition).

Thus, the four theoretical models of household behavior have different implications for the determinants of parent-child coresidence. Thus, we can shed light on which theoretical model of household behavior applies in the case of Japan by examining the determinants of parent-child coresideence.

\section{The Data Source and Sample Selection}

\subsection{The Data Source}

The data source we use is micro data from the 1998 "National Family Survey (in Japanese, Kazoku ni tsuiteno Zenkoku Chousa)" which was conducted in January 1999 and provided by National Family Research of Japan and the Information Center for Social Science Research on Japan, Institute of Social Science, University of Tokyo (SSJ Data Archive).

This survey collects a variety of detailed information on respondents and their family 
members--for example, on the structure of respondents' families, the socioeconomic characteristics of both parents and children, respondents' attitudes towards their children, etc.

This survey surveyed a stratified multistage random sample of 10,500 respondents between the ages of 28 and 77 (born between January 1, 1921 and December 31, 1970) from throughout Japan by the drop-off, pick-up method, resulting in 6,985 responses (a response rate of $66.5 \%)$.

\subsection{Sample Selection}

In this subsection, we discuss the sample we used in our analysis. Of the 6,985 respondents (hereafter called parents (fathers and mothers) or households), 1,070 have no living children, 952 have one living child, 3,067 have two living children, 1,515 have three living children, 372 have four or more living children, and 9 did not indicate how many living children they have. First, we used only the subsample of respondents who have one, two, or three living children. Respondents who have four or more living children provide information only on the three oldest children, so we were forced to drop these respondents. ${ }^{3}$ Second, we used only the subsample of respondents for whom the father is 60 or older (if there is no father, respondents for whom the mother is 60 or older) because we were interested in the living arrangements of elderly parents and their children. Third, we dropped all observations for which all of the necessary information is not available. Restricting the sample to respondents who have one, two and three living children reduced the number of observations from 6,985 to 5,367 , restricting the sample to respondents for whom the father (if there is no father, the mother) is 60 or older reduced the number of observations further to 2,068 , and restricting the sample to respondents for whom all of the necessary information is available reduced the number of observations further to 1,652 .

In addition, we divide the sample into (i) respondents with multiple children (called sample (i), with 1,373 observations), (ii) respondents with multiple children including at least one son (called sample (ii), with 1,125 observations), (iii) respondents with multiple children including at least one daughter (called sample (iii), with 1,060 observations), and (iv) 
respondents with only one child (called sample (iv), with 279 observations).

\section{The Estimation Model and Estimation Method}

We use the following multinomial logit model to test what variables affect the living arrangements (coresidence behavior) of parents and their children:

$$
P(y=j \mid x)={\exp \left(x \beta_{j}\right) / 1+\sum_{\mathrm{h}=1}^{4} \exp \left(x \beta_{h}\right)}_{j=1,2,3,4}
$$

In the case of samples (i), (ii), and (iii), the dependent variable $y$ measures four alternative living arrangements of elderly parents: in the case of sample (i), parents who live with the eldest child (=1); parents who live with a child or children other than the eldest child $(=2)$; parents who live with both the eldest child and other children $(=3)$, and parents who live independently $(=4)$; in the case of sample (ii), parents who live with the eldest son $(=1)$; parents who live with a child (or children) other than the eldest son (=2); parents who live with both the eldest son and other children $(=3)$, and parents who live independently $(=4)$; and in the case of sample (iii), parents who live with the eldest daughter $(=1)$; parents who live with a child (or children) other than the eldest daughter $(=2)$; parents who live with both the eldest daughter and other children ( $=3$ ), and parents who live independently $(=4)$. In the case of samples (i), (ii), and (iii), we estimate equation (1) using a multinomial logit model because the dependent variable $y$ has four unordered response outcomes. ${ }^{4}$ In the case of sample (iv), parents choose between living with their only child $(=1)$ and living independently $(=0)$, and thus we use a logit model to test what variables affect the living arrangements of parents and their only child. When constructing the dependent variables, we classify the categories "the child lives in the same house as his/her parents" and "the child lives in a separate house on the same property as his/her parents" as "the parents live with the child," and we classify "the child lives within walking distance of the parents," "the child lives within one hour of the parents," "the child 
lives within three hours of the parents," and "the child lives more than three hours from the parents" as "the parents live independently."

The explanatory variables include a vector of variables pertaining to the preferences and economic backgrounds of parents and (in the case of sample (i)) the eldest child and other children, (in the case of sample (ii)) the eldest son and other children, (in the case of sample (iii)) the eldest daughter and other children, and (in the case of sample (iv)) the only child.

Our main interest is to shed light on which theoretical model(s) of household behavior apply in Japan by analyzing the determinants of the living arrangements (coresidence behavior) of elderly parents and their children in the case of parents with multiple children and those with only one child. In what follows, we discuss the explanatory variables used in our analysis and their theoretical impact on the living arrangements of parents and their children.

\section{(I) The Dynasty Model}

The two variables we use to examine whether individuals behave according to the dynasty model are hselfempl (a dummy variable that equals one if the father (the mother if there is no father) was a non-professional self-employed worker before retirement) and. hprofl (a dummy variable that equals one if the father (the mother if there is no father) was a professional self-employed worker such as a doctor, lawyer, etc., before retirement) (the base category is fathers (mothers if there is no father) who were salaried workers before retirement). Self-employed households are different from salaried worker households because the former have a family business that they would presumably like to pass on to their children, preferably their eldest son. If the dynasty model applies, the children of self-employed parents will take over the family business in exchange for receiving a bequest (especially the family business), and since family businesses are often located in, or adjacent to, the parents' home, the child who takes over the family business is more likely to live with his/her parents. Thus, if individuals behave according to the dynasty model, we would expect hselfempl and hprofl to increase the probability of the parents living with their children, especially their eldest son. Note that these results could also be consistent with the selfish life cycle model if the child who lives with the 
parents is doing so in return for bequeathing the family business, which presumably generates a considerable cash flow, but in our sample, we find that the incomes of the children of self-employed parents are lower than the incomes of the children of parents in other occupations, which suggests that the explanation based on the selfish life cycle model does not apply.

Another variant of the dynasty model is that parents care about perpetuating the family name or the family line and hence will leave the largest share of their bequest (especially the family home) to the child who carries on the family name or the family line. And it is natural for the child who carries on the family name or the family line to live with the parents since he or she will eventually inherit the family home. If this variant of the dynasty model is valid, parents should be more likely to live with sons who keep their original surnames and daughters who marry a man who adopts their surname and less likely to live with sons who adopt their wife's surname and daughters who adopt their husband's surname. Thus, we test this variant of the dynasty model by including the following variables: essurname (a dummy variable that equals one if there is an eldest son and the eldest son adopts his wife's surname)), ossurname (a dummy variable that equals one if there is at least one son other than the eldest son and at least one of them adopts his wife's surname), edsurname (a dummy variable that equals one if there is an eldest daughter and the eldest daughter married a man who adopted her surname), and odsurname (a dummy variable that equals one if there is at least one daughter other than the eldest daughter and at least one of them married a man who adopted her surname). ${ }^{5}$ If individuals behave according to this variant of the dynasty model, we would expect essurname to reduce the probability of the parents living with the eldest son, ossurname to reduce the probability of the parents living with a child other than the eldest son, edsurname to increase the probability of the parents living with eldest daughter, and odsurname to increase the probability of the parents living with a child other than the eldest daughter. Note that these findings might also be consistent with the selfish life cycle model since those with more noble surnames (who will tend to be relatively wealthy) will be more likely to want to perpetuate the family line and their daughters may be more willing to live with them and to marry a man who is willing to adopt her surname because of the greater financial rewards from doing so, but since we control 
for parental wealth using parental occupation, educational attainment, income, and homeownership status, we believe that we can rule out the explanation based on the selfish life cycle model.

\section{The Selfish Life Cycle Model}

In order to examine whether individuals behave according to the selfish life cycle model, we include hexecutive (a dummy variable that equals one if the father (the mother if there is no father) was an executive before retirement (where executive includes management executive, executive board member, and management-level employee (including government workers)) (the base category is fathers (mothers if there is no father) who were rank-and-file salaried workers before retirement)), peduc (the average educational attainment (in years) of the parents (if there is only one parent, the educational attainment of that parent), pincome (the income of the father and mother combined), ${ }^{6}$ and phouse (a dummy variable that equals one if the parents live in an owner-occupied home). If the father was an executive before retirement, if the parents are highly educated, and/or if the combined income of the parents is high, the parents are presumably relatively wealthy and should have more wealth to leave behind to their children, and thus their children should be more likely to live with them if they are selfishly motivated. By the same token, the children of parents who are homeowners should also be more likely to live with their parents if they are selfishly motivated because they can expect to receive the family home as a bequest. Thus, if the selfish life cycle model applies, we would expect hexecutive, peduc, pincome, and phouse to increase the probability of the parents living with their children. $^{7}$ Note, however, that these results could also be consistent with the (one-sided) altruism model if wealthier parents have larger and more luxurious homes and hence are better able to induce their children to live with them, even if they do not consciously attempt to coerce their children into living with them.

\section{(III) The Altruism Model}

We included variables relating to the educational attainment of the children as a way of testing 
the altruism model directly. In particular, in sample (i), we included eeduc (the educational attainment of the eldest child (in years)) and keduc (the educational attainment of child(ren) other than the eldest child (if the number of such children is two, the average educational attainment of such children); in sample (iv), we included only eeduc as defined above; in sample (ii), we defined eeduc as the educational attainment of the eldest son (in years) and $k e d u c$ as the educational attainment of child(ren) other than the eldest son (if the number of such children is two, the average educational attainment of such children); and in sample (iii), we defined eeduc as the educational attainment of the eldest daughter (in years) and keduc as the educational attainment of child(ren) other than the eldest daughter (if the number of such children is two, the average educational attainment of such children). As Horioka (2002) points out, altruistic parents should leave larger bequests to poorer children, and since education is a good proxy for earning capacity, altruistic parents should leave larger bequests to less educated children. ${ }^{8}$ Moreover, since the family home is often the largest component of parental wealth, it is plausible to assume that altruistic parents will choose to live with the least educated (poorest) child and bequeath the family home to him or her. Thus, we would expect eeduc to reduce the probability of the parents living with the eldest child, son, or daughter and keduc to reduce the probability of the parents living with a child other than the eldest child, son, or daughter. Note, however, that since the wage rate of less educated children is presumably lower than that of more highly educated children, meaning that they have a lower opportunity cost of providing care to their parents, the fact that they are more likely to live with (and to provide care to) their parents in old age could also be consistent with the selfish life cycle model.

We also include a variable pertaining to parental attitudes towards their children to enable us to conduct a further test of the altruism model. In the survey we use in our analysis, respondents were asked if they agree with a number of views concerning their attitudes towards their children, one of which is: "Parents should sacrifice themselves for their children." Respondents were asked to pick from among the following four choices.

(1) I think so. 
(2) I tend to think so.

(3) I tend not to think so.

(4) I do not think so.

We created the variable psacrifice (a dummy variable that equals one if parents think (or tend to think) that parents should sacrifice themselves for their children) and added it to equation (1). This variable is presumably a good proxy for parents who behave according to the altruism model because those who agree with this view are willing to put the interests of their children before their own. However, since it is not obvious whether altruistic parents will be more or less likely to live with their children, it is not possible to predict a priori whether the marginal effect of psacrifice will be positive or negative.

Finally, another way to test the altruism model is to see if variables relating to the dynasty and selfish life cycle models (hselfempl, hprofl, essurname, ossurname, edsurname, odsurname, hexecutive, peduc, pincome, hretired*pincome, and phouse) have the expected impact on the likelihood of parents living with their children. If they do, this constitutes evidence unfavorable to the altruism model because the altruism model predicts that the behavior of parents and children will be motivated by altruism rather than by some sort of quid pro quo.

\section{(IV) Social Norms and Traditions}

One way in which we tested for the importance of social norms is by including elderson (a dummy variable that equals one if the eldest child is a son). If the social norm is for parents to live with their eldest son regardless of whether the eldest son is the eldest child, the fact that the eldest child is a son should raise the probability that the parents live with their eldest child but whether the eldest son is the eldest child should not affect the probability that the parents live with their eldest son.

Another way in which we tested for the importance of Japanese social norms and traditions was by using two variables created from the same question on parental attitudes towards their children that was discussed in section III above. Two other views that are asked 
about are as follows:

(a) Children should live with their parents when the parents become old and cannot take care of themselves.

(b) It is an eldest son's duty to take care of his parents.

View (a) is consistent with the Japanese social norm or tradition (based on Confucian teachings) that children should live with their parents and take care of them when their parents become old, while view (b) is consistent with the Japanese social norm or tradition that more is expected of the eldest son. Thus, we created the variables pchildduty and pesonduty (dummy variables that equal one if the respondent agrees (or tends to agree) with views (a) and (b), respectively), and added them to equation (1). If individuals behave according to Japanese social norms and traditions, we would expect pchildduty to increase the probability of the parents living with the eldest son or with a child other than the eldest son and pesonduty to increase the probability of the parents living with the eldest son. ${ }^{9}$

It is possible that parents tend to live with their eldest son not because of social norms but because the eldest son is likely to be the first to marry and purchase a house, meaning that parents will be able to coreside longer (and reap more benefits) if they coreside with their

eldest son. Similarly, parents may choose to live with their eldest son even if they have a daughter who is older than their eldest son not because of social norms but because Japanese women tend to marry older men to a greater extent than Western women, meaning that the issue of coresidence is likely to arise earlier in the case of their husband's parents than in the case of their own parents. This argument can explain why eldest sons are more likely to live with their parents (even if there is a daughter who is older than the eldest son) but does not explain why parental attitudes towards their children affect their probability of living with their children.

(V) Control Variables

Finally, we discuss the control variables we included. First, we included the following variables relating to the parents: psingle (a dummy variable that equals one if there is only one 
parent), phealth (a dummy variable that equals one if one or both parents are unhealthy), page (the age of the parent if there is only one parent and the average age of the parents if there are two parents), hretired (a dummy variable that equals one if the father (the mother if there is no father) is currently retired), and hpartunempl (a dummy variable that equals one if the father (the mother if there is no father) was a part-time worker or unemployed before retirement.

Next, we included four control variables relating to the composition of children: eson (a dummy variable that equals one if there is an eldest son), edaughter (a dummy variable that equals one if there is an eldest daughter), oson (a dummy variable that equals one if there is at least one son other than the eldest son), and odaughter (a dummy variable that equals one if there is at least one daughter other than the eldest daughter). ${ }^{10}$

In addition, we included the following variables relating to the marital status of the children: In sample (i), we included esingle (a dummy variable that equals one if the eldest child is single), edivorce (a dummy variable that equals one if the eldest child is divorced), ksingle (a dummy variable that equals one if at least one child other than the eldest child is single), and kdivorce (a dummy variable that equals one if at least one child other than the eldest child is single); in sample (iv), we included only esingle (a dummy variable that equals one if the only child is single) and edivorce (a dummy variable that equals one if the only child is divorced); in sample (ii), we defined esingle as a dummy variable that equals one if the eldest son is single, edivorce as a dummy variable that equals one if the eldest son is divorced, ksingle as a dummy variable that equals one if at least one child other than the eldest son is single, and kdivorced as a dummy variable that equals one if at least one child other than the eldest son is single; and in sample (iii), we defined esingle as a dummy variable that equals one if the eldest daughter is single, edivorce as a dummy variable that equals one if the eldest daughter is divorced, ksingle as a dummy variable that equals one if at least one child other than the eldest daughter is single, and kdivorced as a dummy variable that equals one if at least one child other than the eldest daughter is divorced;

Finally, we included the following variables relating to the ages of the children: In sample (i), we included eage (the age of the eldest child) and kage (the average age of children 
other than the eldest child); in sample (iv), we included eage (the age of the only child); in sample (ii), we defined eage as the age of the eldest son and kage as the average age of children other than the eldest son; and in sample (iii), we defined eage as the age of the eldest daughter and kage as the average age of children other than the eldest daughter;

\section{Descriptive Statistics}

Before discussing the estimation results, we present some descriptive statistics to give the reader a general idea of the living arrangements of elderly parents and their children in Japan. The upper row of Table 1 shows with which child elderly parents live, and as can be seen from this row, 53.4 percent of elderly parents with only one child live with their child, and about 20-40 percent of elderly parents with two or more children live with their child or children. Looking more specifically at with which child elderly parents live, an interesting pattern emerges: if elderly parents have an eldest son, they are much more likely to live with their eldest son than to live with children other than the eldest son (43.7 percent vs. 13.8 percent). Second, the percentage of parents who live with their eldest child is only about 22.3 percent. That is, parents are more likely to live with their eldest son even if the eldest son is not the eldest child. This is consistent with the Japanese social norm that the eldest son should live with,his parents and take care of them during old age.

We look next at data on sons who adopt their wives' surname and daughters whose husbands adopt their surname. Such data shed light on the importance of the dynasty model because a son who adopts his wife's surname cannot carry on his parents' family line, and conversely, a daughter whose husband adopts her surname can carry on her parents' family line. If the dynasty model applies and parents care about perpetuating the family line, we would not expect parents with only one son and no daughters (hereafter referred to as "single sons") to allow their sons to adopt their wives' surname, and conversely, we would expect parents with only daughters to encourage at least one of their daughters to marry a man who is willing to adopt their surname.

Looking at the results, only 3.2 percent of sons who are only children and 2.1 percent 
of eldest sons adopt their wives' surnames whereas a full 12.9 percent of second-born sons and third-born sons do so, which indicates that sons who are only children and eldest sons are far less likely to adopt their wives' surnames. On the other hand, 7.2 percent of daughters who are only children, 14.6 percent of eldest daughters, and 13.3 percent of eldest daughters who have only sisters marry a man who adopts her surname, whereas only 1.7 percent of eldest daughters with brothers marry such a man. Furthermore, 16.9 percent of daughters other than eldest daughters who have only sisters marry a man who adopts her surname, whereas only 0.9 percent of daughters other than eldest daughters with brothers marry such a man. Thus, households that have at least one son rarely have daughters who marry men who adopt their surnames (because if there is at least one son, the son can carry on the family line), whereas daughters with no brothers are much more likely to marry men who adopt their surnames in order to perpetuate the family line. These results are consistent with the dynasty model because they underscore the eagerness of parents and their children to perpetuate the family line.

\section{Estimation Results}

In this section, we present our estimation results concerning the determinants of the living arrangements (coresidence behavior) of elderly parents and their children. Table 2 shows the results for samples (i) and (iv), Table 3 the results for sample (ii), and Table 4 the results for sample (iii). To conserve on space, we present only the marginal effects and standard errors of each coefficient. We organize our discussion by theoretical model.

First, we discuss our estimation results pertaining to the dynasty model. Looking first at the marginal effects of hselfempl and hprofl, our results show that the probability that parents live with their eldest son is 7.3 (18.7) percentage points higher if the husband was a non-professional (professional) self-employed worker before retirement than if he was a salaried worker before retirement. Similarly, the probability that parents live independently is 7.1 (15.8) percentage points lower if the husband was a non-professional (professional) self-employed worker before retirement than if he was a salaried worker before retirement. 
These results are presumably due to the fact that self-employed households are different from salaried worker households in that the former have a family business that they would like to pass on their children, especially their eldest son, and the child who carries on the family business is more likely to live with his or her parents because he or she will inherit the family business (which is often located in, or adjacent to, the family home). Thus, our result is consistent with the dynasty model.

Turning to the marginal effects of the variables pertaining to whether or not sons adopt their wife's surname and whether or not daughters marry a man who adopts their surname, the results show that the probability that parents live with their eldest son is 27.5 percentage points lower if their eldest son adopts his wife's surname; that the probability that parents live with their eldest daughter is a full 46.6 percentage points higher, the probability that parents live with a child other than the eldest daughter is 11.3 percentage points lower, and the probability that parents live independently is 27.4 percentage points lower if their eldest daughter marries a man who adopts her surname; and that the probability that parents live with a child other than their eldest daughter is 12.0 percentage points higher if a daughter other than their eldest daughter marries a man who adopts her surname. All of these results suggest that parents have a strong tendency to live with children who carry on their surname, which in turn suggests that the dynasty model is applicable in Japan.

Next, we discuss our estimation results pertaining to the selfish life cycle model. Looking first at the marginal effect of hexecutive, our results show that the probability that parents live with a child other than the eldest son is 7.5 percentage points higher, the probability that parents live with the eldest daughter is 6.8 percentage points higher, and the probability that parents live independently is 8.6 percentage points lower if the father was an executive before retirement than if the father was a rank-and-file salaried worker before retirement. The children of executives, who are presumably relatively wealthy, should be more likely to live with their parents if they are selfishly motivated and thus this finding is consistent with the selfish life cycle model (as well as with the altruism model, as discussed in section 2).

Turning to the marginal effect of phouse, our results show that the probability that 
parents live with their eldest child is 10.4 percentage points higher, the probability that parents live with their eldest son is 17.6 percentage points higher, and the probability that parents live independently is 14.5 to 17.9 percentage points lower if they are homeowners than if they are renters. The children of parents who are homeowners should be more likely to live with their parents if they are selfishly motivated because they can enhance their chances of receiving the family home as a bequest by living with the parents, and thus these results are consistent with the selfish life cycle model (as well as with the altruism model as discussed in section 2).

Turning to the marginal effect of peduc, our results show that well-educated parents are, if anything, less likely to live with their eldest child, especially their eldest son, and more likely to live independently than less educated parents. This result appears to be inconsistent with the selfish life cycle model because well-educated parents are presumably relatively wealthy and selfishly motivated children should be more likely to live with their parents if their parents are relatively wealthy. This finding is also obtained by Iwamoto and Fukui (2001), and one possible explanation for it is that parents value their privacy and prefer to live separately from their children if they are relatively wealthy and can afford to do so.

Turning to the marginal effects of pincome and hretired*pincome, the marginal effects of these variables are significant in only one case, indicating that parental income does not have a significant impact on the living arrangements of parents and children. This result is also hostile to the selfish life cycle model because selfishly motivated children should be more likely to live their parents if their parents are relatively wealthy.

Third, we discuss our estimation results pertaining to the altruism model. Looking at the marginal effect of eeduc, our results show that parents are less likely to live with their eldest child or eldest son and more likely to live independently if their eldest child or eldest son is well-educated. Moreover, the marginal effects of keduc show that parents are more likely to live with their eldest child and also more likely to live independently if their other children are well-educated. These results are consistent with the altruism model because education is a good proxy for earnings capacity and altruistic parents should show a tendency to leave a larger bequest to (and live with) less educated (poorer) children than with better educated (wealthier) 
children but are also consistent with the selfish life cycle model, as noted in section 2.

However, the marginal effect of psacrifice is not significant in any case except in the case of respondents with only one child, which constitutes evidence against the altruism model. Finally, the fact that the impact of a number of variables relating to the dynasty and selfish life cycle models were found to be significant and consistent with these models constitutes further evidence against the altruism model.

Fourth, we discuss our estimation results pertaining to Japanese social norms and traditions. Looking first at the marginal effects of variables pertaining to parental attitudes towards their children, the marginal effect of pchildduty imply that the probability that parents live independently is as much as 7.2 percentage points lower if they feel that children should live with their parents when the parents become old and cannot take care of themselves than if they do not hold this view. Second, the marginal effect of pesonduty implies that the probability that parents live with the eldest son is 6.1 percentage points higher and the probability that parents live with children other than the eldest son is 4.3 percentage points lower if parents feel that it is an eldest son's duty to take care of his parents than if they do not hold this view. Both of these results suggest that Japanese social norms and traditions influence the coresidence decisions of Japanese parents.

We next look at the marginal effect of elderson, which sheds further light on the importance of social norms. If there is a social norm that parents should live with their eldest son, the probability that parents live with their eldest child should be significantly higher and the probability that parents live with children other than the eldest son and the probability that parents live independently should be significantly lower if the eldest child is a son, and the results using sample (i) confirm these results: the former probability is 24.3 percentage points higher and the second and third probabilities are 16.4 and 7.1 percentage points lower if the eldest child is a son. Moreover, if there is a social norm that parents should live with their eldest son, they should live with the eldest son regardless of whether the eldest son is the eldest child, and thus elderson should not have a significant impact on the probability that parents live with their eldest son and this expectation is confirmed in the results using sample 
(ii).

Finally, we discuss the impact of the control variables. The marginal effects of psingle show that the probability that parents live with their children is as much as 11.9 percentage points higher and that the probability that parents live independently is as much as 17.2 percentage points lower for single-parent households than for two-parent households, which suggests that single parents are more likely to live with their children than two-parent households. These are plausible results because, in two-parent households, the parents can take care of one other, whereas a single parent does not have this option and hence will be more likely to require the assistance of his/her children.

To summarize our findings in this section, the living arrangements (co-residence behavior) of elderly parents and their children in Japan are consistent in part with all four explanations considered (the dynasty model, the selfish life cycle model, the altruism model, and social norms and traditions) but most strongly support the life cycle and dynasty models (both of which assume selfishly motivated parents) and social norms and traditions and provide the least support for the altruism model.

\section{Conclusion}

In this paper, we analyzed the determinants of the living arrangements (coresidence behavior) of elderly parents and their children (whether elderly parents live with their children, and if so, with which child) in Japan using micro data from the 1998 "National Family Survey (in Japanese, Kazoku ni tsuiteno Zenkoku Chousa)," which was conducted in January 1999 and provided by the National Family Research of Japan and the Information Center for Social Science Research on Japan, Institute of Social Science, University of Tokyo (SSJ Data Archive).

Our results provide support for all four explanations of coresidence behavior but especially for the life cycle and dynasty models (both of which assume selfishly motivated parents) and social norms and traditions: The fact that parents who were self-employed before retirement are more likely to live with their children, the fact that parents are less likely to live 
with sons who adopt their wife's surname, and the fact that parents are more likely to live with daughters whose husbands adopt their surname constitute evidence in favor of the dynasty model. The fact that parents who were (relatively wealthy) executives before retirement and parents who are homeowners are more likely to live with their children and the fact that parents are more likely to live with less educated children constitute evidence in favor of the selfish life cycle model (or the altruism model). And the fact that parental attitudes toward their children affect their coresidence behavior, the fact that parents are more likely to live with their eldest child if their eldest child is a son, and the fact that parents are most likely to live with their eldest son even if he is not the eldest child constitute evidence in favor of social norms and traditions.

Turning to a comparison of our results with those of previous studies, our results are consistent with the results of Ohtake (1991), Ohtake and Horioka (1994), Horioka, et al. (2000), Iwamoto and Fukui (2001), Yamada (2006), and Kureishi and Wakabayashi (2007) in that we find that the coresidence behavior of parents and children in Japan is in part selfishly motivated. ${ }^{11}$ Moreover, our results are consistent with the results of Ando, et al. (1986) and Iwamoto and Fukui (2001) in that we find that the coresidence behavior of parents and children in Japan is partly motivated by a desire to perpetuate the family business. Finally, our results are consistent with Martin and Tsuya (1991) and Tsuya and Martin (1992) in that we find that the coresidence behavior of parents and children is influenced by social norms. However, as far as we know, our study is the first to simultaneously test for the applicability of the four possible explanations of the coresidence behavior of parents and children in Japan, and this was made possible by our richer data set, which includes detailed information on siblings and parental attitudes towards their children.

We turn finally to directions for further research. The survey we use in our analysis collects information on family structure and sibling composition, making it ideal for the purposes of the analysis here, but information on many socioeconomic characteristics (for example, the financial assets of parents and children, the income of each child, transfers from parents to each child and vice versa, etc.) is not available. One direction for further research 
is to find a data source that includes information on these variables so that we can do a more rigorous analysis, especially of the selfish life cycle model.

Another shortcoming of our analysis is that we used attitudinal data without taking account of the possibility that respondents may try to justify their own behavior when responding to attitudinal questions. Finding a way to eliminate the bias caused by this problem is another possible avenue for further research.

Turning finally to the policy implications of our findings, our finding that the living arrangements (coresidence behavior) of elderly parents and their children is in part selfishly motivated suggests that the selfish life cycle model applies in Japan to at least some extent, and this, in turn, implies that the aging of the population will cause Japan's household saving rate to decline because elderly parents will not need to save in order to leave unrequited bequests to their children. Moreover, this, in turn, may cause interest rates in Japan to rise unless the decline in household saving is fully offset by increases in corporate and/or government saving and/or increases in capital inflows from abroad. 


\section{References}

Ando, Albert, Michiko Yamashita, and Junki Murayama. 1986. "Raifu Saikuru Kasetsu ni Motozuku Shouhi/Chochiku no Koudou Bunseki (A Behavioral Analysis of Consumption and Saving Based on the Life Cycle Hypothesis).” Keizai Bunseki 101:25-139 (in Japanese).

Barro, Robert J. 1974. “Are Government Bonds Net Wealth?” Journal of Political Economy 82:1095-1117.

Becker, Gary S. 1974. "A Theory of Social Interactions.” Journal of Political Economy 82:1063-1093. . 1981. A Treatise on the Family. Cambridge, Massachusetts, USA:

Harvard University Press.

1991. A Treatise on the Family, enlarged edition. Cambridge, Massachusetts, USA: Harvard University Press.

Berhman, Jere R., Robert A. Pollak, and Paul Taubman. 1982. "Parental Preferences and Provision for Progeny.” Journal of Political Economy 90:52-73.

Bernheim, B. Douglas, Andrei Shleifer, and Lawrence H. Summers. 1985. "The Strategic Bequest Motive.” Journal of Political Economy 93:1045-1076.

Checkovich, Tennille J., and Steven Stern. 2002. "Caregiving Responsibilities of Adult Siblings with Elderly Parents." Journal of Human Resources 37:441-478.

Chu, C. Y. Cyrus. 1991. "Primogeniture.” Journal of Political Economy 99:78-99.

Dekle, Robert. 1989. "A Simulation Model of Saving, Residential Choice, and Bequests of the Japanese Elderly." Economics Letters 29:129-133.

Dekle, Robert. 1990. "Do the Japanese Elderly Reduce Their Total Wealth? A New Look with Different Data." Journal of the Japanese and International Economies 4:309-317.

Engers, Maxim, and Steven N. Stern. 2002. "Long Term Care and Family Bargaining." International Economic Review, 43:73-114.

Greene, William. H. 2003. Econometric Analysis, 5th edition. Upper Saddle River, New Jersey, USA: Prentice Hall.

Hayashi, Fumio. 1995. "Is the Japanese Extended Family Altruistically Linked? A Test 
Based on Engel Curves." Journal of Political Economy 103:661-74.

Hayashi, Fumio. 1997. "Is the Japanese Family Altruistically Linked? A Test Based on Engel Curves." In Understanding Saving: Evidence from the United States and Japan, ed. Fumio Hayashi. Cambridge, Massachusetts, USA: MIT Press.

Hiedemann, Bridget, and Steven Stern. 1999. "Strategic Play among Family Members when Making Long-Term Care Decisions.” Journal of Economic Behavior and Organization 40:29-57.

Hoerger, Thomas J., Gabriel A. Picone, and Frank A. Sloan. 1996. "Public Subsidies, Private Provision of Care and Living Arrangements of the Elderly." Review of Economics and Statistics 78:428-440.

Horioka, Charles Yuji. 2002a. "Are the Japanese Selfish, Altruistic or Dynastic?" Japanese Economic Review 53:26-54.

Horioka, Charles Yuji. 2002b. "Nihonjin ha Rikoteki ka Ritateki ka Ouchouteki ka? (Are the Japanese Selfish, Altruistic or Dynastic?).” In Gendai Keizaigaku no Chouryuu 2002 (Trends in Contemporary Economics), ed. Keijiro Otsuka, Shinichi Fukuda, Mikio Nakayama, and Yuzo Honda. Tokyo: Toyo Keizai Shinposha (in Japanese).

Horioka, Charles Yuji; Hideki Fujisaki, Wako Watanabe, and Takatsugu Kouno. 2000. "Are Americans More Altruistic than the Japanese? A U.S.-Japan Comparison of Saving and Bequest Motives.” International Economic Journal 14:1-31.

Iwamoto, Yasushi, and Tadashi Fukui. 2001. "Doukyo Sentaku ni okeru Shotoku no Eikyou (The Effect of Incomes on Living Arrangements)." Nihon Keizai Kenkyu 151:21-43 (in Japanese).

Kotlikoff, Laurence. J., and John N. Morris. 1990. “Why Don’t the Elderly Live with Their Children? A New Look." In Issues in the Economics of Aging, ed. David A. Wise. Chicago: The University of Chicago Press.

Konrad, Kai A., Harald Kunemund, Kjell Erik Lommerud, and Julio R. Robledo. 2002. "Geography of the Family." American Economic Review 92:981-998.

Kureishi, Wataru, and Midori Wakabayashi. 2007. "Why Do First-born Children Live 
with Parents? Geography of the Family in Japan.” Mimeo., Institute of Social and Economic Research, Osaka University, Osaka, Japan.

Martin, Linda G., and Noriko O. Tsuya. 1991. "Interactions of Middle-Aged Japanese with Their Parents. Population Studies 45:299-311.

Modigliani, Franco, and Brumberg, Richard (1955), "Utility Analysis and the Consumption Function: An Interpretation of Cross-Section Data," in Kenneth K. Kurihara, ed., Post-Keynesian Economics (New Brunswick, N.J.: Rutgers University Press), pp. $388-436$.

Ohtake, Fumio. 1991. "Bequest Motives of Aged Households in Japan." Ricerche Economche 45:283-306.

and Charles Yuji Horioka. 1994. "Chochiku Douki (Savings

Motives).” In Nihon no Shotoku to Tomi no Bunpai (The Distribution of Income and Wealth in Japan), ed. Tsuneo Ishikawa. Tokyo: University of Tokyo Press (in Japanese).

Sakudo, Mari (2007), "Strategic Interactions between Parents and Daughters: Co-residence, Marriage, and Intergenerational Transfers in Japan," mimeo., Department of Economics, University of Chicago.

Stern, Steve. 1995. "Estimating Family Long-Term Care Decisions in the Presence of Endogenous Child Characteristics.” Journal of Human Resources 30:551-580.

Train, Kenneth E. 2003. Discrete Choice Methods with Simulation. Cambridge, England: Cambridge University Press.

Tsuya, Noriko O., and Linda G. Martin. 1992. "Living Arrangements of Elderly Japanese and Attitudes toward Inheritance." Journal of Gerontology: Social Sciences 47:S45-54.

Yamada, Ken. 2006. "Intra-family Transfers in Japan: Intergenerational Co-residence, Distance, and Contact." Applied Economics 38:1839-1861.

Yashiro, Naohiro., et al. 1997. "Koureika no Keizai Bunseki (The Economic Analysis of Aging).” Keizai Bunseki 151:3-129 (in Japanese).

Wooldridge, Jeffrey M. 2001. Econometric Analysis of Cross Section and Panel Data. 
Cambridge, Massachusetts, USA: MIT Press. 
Table 1: Descriptive Statistics

\begin{tabular}{|c|c|c|c|c|}
\hline & Sample (i) & Sample (ii) & Sample (iii) & Sample (iv) \\
\hline & $\begin{array}{l}\text { Parents with two or } \\
\text { more children ( } 1373 \\
\text { observations) }\end{array}$ & $\begin{array}{l}\text { Parents with two or } \\
\text { more children and } \\
\text { with at least one son } \\
\text { (1125 observations) }\end{array}$ & $\begin{array}{c}\text { Parents with two or } \\
\text { more children and } \\
\text { with at least one } \\
\text { daughter ( } 1060 \\
\text { observations) } \\
\end{array}$ & $\begin{array}{l}\text { Parents with only } \\
\text { one child ( } 279 \\
\text { observations) }\end{array}$ \\
\hline \multicolumn{5}{|l|}{ Respondents live } \\
\hline with eldest child/son/daughter/child & $295(21.49)$ & $492(43.73)$ & $239(22.55)$ & $149(53.41)$ \\
\hline with other children & $368(26.80)$ & $155(13.78)$ & $254(23.96)$ & - \\
\hline with both & $143(10.42)$ & $28(2.49)$ & $132(12.45)$ & - \\
\hline independently & $567(41.30)$ & $450(40.00)$ & $435(41.04)$ & $130(46.59)$ \\
\hline \multicolumn{5}{|l|}{ Father's occupation } \\
\hline hexecutive & $159(11.58)$ & $129(11.47)$ & $122(11.51)$ & $36(12.90)$ \\
\hline hprofl & $26(1.89)$ & $20(1.78)$ & $20(1.89)$ & $4(1.43)$ \\
\hline hselfempl & $317(23.09)$ & $264(23.47)$ & $243(22.92)$ & $38(13.62)$ \\
\hline hsalaried & $674(49.09)$ & $550(48.89)$ & $520(49.06)$ & $163(58.42)$ \\
\hline hpartunemp & $197(14.35)$ & $162(14.40)$ & $155(14.62)$ & $38(13.62)$ \\
\hline hretired & $843(51.03)$ & $555(49.33)$ & $520(49.06)$ & $157(56.27)$ \\
\hline essurname & $16(1.17)$ & $24(2.13)$ & - & $9(3.23)$ \\
\hline edsurname & $41(2.99)$ & - & $47(4.43)$ & $20(7.17)$ \\
\hline ossurname & $45(3.28)$ & $145(12.89)$ & $30(2.83)$ & - \\
\hline odsurname & $24(1.75)$ & $38(3.38)$ & $49(4.62)$ & - \\
\hline peduc* & $11.20(1.96)$ & $11.18(1.97)$ & $11.20(1.97)$ & $11.47(1.90)$ \\
\hline pincome* (million yen) & $4.82(3.98)$ & $4.81(4.05)$ & $4.85(4.03)$ & $4.33(3.79)$ \\
\hline phouse & $1,221(88.93)$ & $1,003(89.16)$ & $947(89.34)$ & $229(82.08)$ \\
\hline eeduc* (years) & $13.72(1.96)$ & $13.98(2.12)$ & $13.34(1.67)$ & $13.76(2.08)$ \\
\hline oeduc* (years) & $13.59(1.84)$ & $13.60(1.87)$ & $13.77(1.91)$ & - \\
\hline \multicolumn{5}{|l|}{ Parents attitude towards their children } \\
\hline psacrifice & $866(63.07)$ & $717(63.73)$ & $666(62.83)$ & $171(61.29)$ \\
\hline pchildduty & $870(63.36)$ & $731(64.98)$ & $667(62.92)$ & $182(65.23)$ \\
\hline pesonduty & $618(45.01)$ & $542(48.18)$ & $479(45.19)$ & $113(40.50)$ \\
\hline psingle & $275(20.03)$ & $232(20.62)$ & $215(20.28)$ & $88(31.54)$ \\
\hline phealth & $713(51.93)$ & $597(53.07)$ & $561(52.92)$ & $143(51.25)$ \\
\hline \multicolumn{5}{|l|}{ Children's marriage condition } \\
\hline esingle & $292(21.27)$ & $338(30.04)$ & $202(19.06)$ & $105(37.63)$ \\
\hline emarriage & $1,031(75.09)$ & $760(67.56)$ & $815(76.89)$ & $165(59.14)$ \\
\hline edivorce & $50(3.64)$ & $27(2.40)$ & $43(4.06)$ & $9(3.23)$ \\
\hline osingle & $499(36.34)$ & $341(30.31)$ & $391(36.89)$ & - \\
\hline omarriage & $964(70.21)$ & $850(75.56)$ & $756(71.32)$ & - \\
\hline odivorce & $50(3.64)$ & $53(4.71)$ & $38(3.58)$ & - \\
\hline page $*$ (years old) & $64.72(6.75)$ & $64.75(6.77)$ & $64.69(6.69)$ & $64.11(8.36)$ \\
\hline eage* (years old) & $39.30(7.46)$ & $37.97(7.78)$ & $37.90(7.75)$ & $36.42(9.70)$ \\
\hline kage* $^{*}$ (years old $)$ & $35.41(7.54)$ & $36.60(7.63)$ & $36.51(7.61)$ & - \\
\hline elderson & $714(52.00)$ & $714(63.47)$ & $401(37.83)$ & $150(53.76)$ \\
\hline
\end{tabular}

Data source: The 1998 "National Family Survey (in Japanese, Kazoku ni tsuiteno Zenkoku Chousa), " conducted by National Family Research of Japan

Notes: Refer to the main text for variable definitions. The first figure indicates the number of observations and the second figure (in parentheses) denotes the share of the total sample (except where otherwise noted). hsalaried is a dummy variable that equals one if the husband was a rank-and-file salaried worker before retirement.

*The first figure denotes the mean and the second figure (in parentheses) denotes the standard deviation. 
Table 2: Estimation Results for Samples (i) and (iv) (Marginal Effects)

\begin{tabular}{|c|c|c|c|c|c|}
\hline \multirow[b]{2}{*}{ Dependent variable } & \multicolumn{4}{|c|}{ Sample (i) (1373 observations) } & \multirow{2}{*}{$\begin{array}{l}\text { Sample (iv) (279 obs.) } \\
\text { Parents live with their } \\
\text { only child }(=1) \text { or live } \\
\text { independently }(=0)\end{array}$} \\
\hline & $\begin{array}{l}\text { Parents live } \\
\text { with their } \\
\text { eldest child } \\
\qquad=1)\end{array}$ & $\begin{array}{l}\text { Parents live with } \\
\text { children other than } \\
\text { their eldest child } \\
\qquad(=2)\end{array}$ & $\begin{array}{l}\text { Parents live with } \\
\text { both their eldest } \\
\text { child and other } \\
\text { children }(=3)\end{array}$ & $\begin{array}{c}\text { Parents live } \\
\text { independently } \\
\qquad=4)\end{array}$ & \\
\hline & (i) & (ii) & (iii) & (iv) & (v) \\
\hline \multirow{2}{*}{ hselfempl } & 0.027 & 0.012 & 0.027 & $-0.065 * *$ & 0.157 \\
\hline & $(0.027)$ & $(0.030)$ & $(0.445)$ & $(0.032)$ & $(0.103)$ \\
\hline \multirow{3}{*}{ hprofl } & 0.126 & 0.023 & -0.048 & -0.101 & 0.159 \\
\hline & $(0.082)$ & $(0.081)$ & $(0.044)$ & $(0.079)$ & $(0.229)$ \\
\hline & -0.102 & -0.009 & $-0.105 * * *$ & $0.216 *$ & - \\
\hline essurname & $(0.082)$ & $(0.112)$ & $(0.006)$ & $(0.125)$ & - \\
\hline \multirow{3}{*}{ edsurname } & $0.411 * * *$ & $-0.160 * * *$ & 0.061 & $-0.312 * * *$ & $0.458 * * *$ \\
\hline & $(0.068)$ & $(0.045)$ & $(0.056)$ & $(0.046)$ & $(0.050)$ \\
\hline & $0.138 * *$ & 0.061 & 0.006 & $-0.206 * * *$ & - \\
\hline ossurname & $(0.060)$ & $(0.084)$ & $(0.072)$ & $(0.064)$ & - \\
\hline \multirow{2}{*}{ odsurname } & $-0.218 * * *$ & $0.237 * *$ & $0.281 * * *$ & $-0.300 * * *$ & - \\
\hline & $(0.009)$ & $(0.103)$ & $(0.094)$ & $(0.058)$ & - \\
\hline \multirow{2}{*}{ hexecutive } & 0.004 & 0.045 & 0.008 & -0.057 & 0.111 \\
\hline & $(0.036)$ & $(0.039)$ & $(0.023)$ & $(0.040)$ & $(0.108)$ \\
\hline \multirow{2}{*}{ peduc } & $-0.018 * * *$ & -0.001 & 0.000 & $0.018 * *$ & -0.015 \\
\hline & $(0.006)$ & $(0.007)$ & $(0.004)$ & $(0.007)$ & $(0.023)$ \\
\hline \multirow{3}{*}{ phouse } & $0.104 * * *$ & 0.048 & 0.026 & $-0.178 * * *$ & 0.143 \\
\hline & $(0.028)$ & $(0.033)$ & $(0.017)$ & $(0.039)$ & $(0.100)$ \\
\hline & -0.004 & 0.002 & 0.001 & 0.001 & -0.008 \\
\hline \multirow{2}{*}{ pincome } & $(0.003)$ & $(0.004)$ & $(0.002)$ & $(0.004)$ & $(0.013)$ \\
\hline & -0.007 & 0.002 & $0.009 * *$ & -0.004 & 0.022 \\
\hline hretired $^{*}$ pincome & $(0.007)$ & $(0.006)$ & $(0.004)$ & $(0.007)$ & $(0.025)$ \\
\hline \multirow{2}{*}{ eeduc } & $-0.016 * * *$ & -0.003 & 0.002 & $0.017 * *$ & -0.033 \\
\hline & $(0.006)$ & $(0.007)$ & $(0.004)$ & $(0.008)$ & $(0.021)$ \\
\hline \multirow{2}{*}{ keduc } & $0.014 * *$ & -0.008 & $-0.020 * * *$ & $0.014 *$ & - \\
\hline & $(0.007)$ & $(0.007)$ & $(0.004)$ & $(0.008)$ & - \\
\hline \multirow{2}{*}{ psacrifice } & -0.007 & 0.036 & 0.003 & -0.032 & $0.128 *$ \\
\hline & $(0.021)$ & $(0.023)$ & $(0.014)$ & $(0.025)$ & $(0.075)$ \\
\hline \multirow{2}{*}{ pchildduty } & 0.035 & 0.022 & 0.015 & $-0.072 * * *$ & 0.121 \\
\hline & $(0.023)$ & $(0.024)$ & $(0.015)$ & $(0.027)$ & $(0.083)$ \\
\hline \multirow{2}{*}{ pesonduty } & 0.016 & -0.019 & 0.003 & 0.000 & -0.076 \\
\hline & $(0.022)$ & $(0.025)$ & $(0.015)$ & $(0.027)$ & $(0.080)$ \\
\hline \multirow{2}{*}{ elderson } & $0.243 * * *$ & $-0.164 * * *$ & -0.007 & $-0.071 * *$ & - \\
\hline & $(0.027)$ & $(0.029)$ & $(0.018)$ & $(0.033)$ & - \\
\hline \multirow{2}{*}{ psingle } & 0.036 & $0.119 * * *$ & -0.001 & $-0.154 * * *$ & 0.126 \\
\hline & $(0.028)$ & $(0.033)$ & $(0.018)$ & $(0.033)$ & $(0.090)$ \\
\hline \multirow{2}{*}{ eson } & -0.069 & $0.114 * *$ & 0.015 & -0.060 & 0.064 \\
\hline & $(0.053)$ & $(0.033)$ & $(0.024)$ & $(0.052)$ & $(0.079)$ \\
\hline \multirow{2}{*}{ edaughter } & -0.003 & 0.059 & $0.046 * *$ & $-0.101 * *$ & - \\
\hline & $(0.031)$ & $(0.036)$ & $(0.018)$ & $(0.044)$ & - \\
\hline & 0.032 & 0.008 & 0.028 & $-0.068 *$ & - \\
\hline oson & $(0.033)$ & $(0.036)$ & $(0.021)$ & $(0.041)$ & - \\
\hline & $0.073 *$ & -0.021 & 0.008 & -0.059 & - \\
\hline odaughter & $(0.042)$ & $(0.034)$ & $(0.023)$ & $(0.042)$ & - \\
\hline
\end{tabular}

Data source: The same as Table 1.

Notes: The figures represent marginal effects evaluated at the sample mean and their standard errors.

The results for sample (i) were estimated using a multinomial logit model, while the results for sample (iv) were estimated using a logit model.

We used the STATA command margeff8, which analytically estimates marginal effects and standard errors for marginal effects using the delta method.

phealth, hretired, hpartunemp, page, eage, kage, esingle, edivorce, ksingle, kdivorce, and a constant term were included in specifications (except that kage, ksingle, and kdivorce were not included in the results for sample (iv)), but their coefficients were suppressed.

$*$ denotes significant at the $10 \%$ level, $* *$ denotes significant at the $5 \%$ level, and $* * *$ denotes significant at the $1 \%$ level. 
Table 3: Estimation Results for Sample (ii) (Marginal Effects)

\begin{tabular}{|c|c|c|c|c|}
\hline \multirow[b]{2}{*}{ Dependent variable } & \multicolumn{4}{|c|}{ Sample (ii) (1125 observations) } \\
\hline & $\begin{array}{c}\text { Parents live with } \\
\text { their eldest son } \\
(=1)\end{array}$ & $\begin{array}{l}\text { Parents live with } \\
\text { children other than } \\
\text { their eldest son } \\
(=2)\end{array}$ & $\begin{array}{l}\text { Parents live with } \\
\text { both their eldest son } \\
\text { and other children } \\
(=3)\end{array}$ & $\begin{array}{l}\text { Parents live } \\
\text { independently } \\
\qquad(=4)\end{array}$ \\
\hline & (vi) & (vii) & (viii) & (ix) \\
\hline \multirow{2}{*}{ hselfempl } & $0.073 *$ & 0.013 & -0.014 & $-0.071 * *$ \\
\hline & $(0.038)$ & $(0.026)$ & $(0.010)$ & $(0.036)$ \\
\hline \multirow{3}{*}{ hprofl } & $0.187 *$ & -0.004 & $-0.026 * * *$ & $-0.158 * *$ \\
\hline & $(0.098)$ & $(0.073)$ & $(0.004)$ & $(0.077)$ \\
\hline & $-0.275 * * *$ & 0.042 & 0.023 & $0.209 * *$ \\
\hline \multirow{2}{*}{ essurname } & $(0.090)$ & $(0.073)$ & $(0.041)$ & $(0.094)$ \\
\hline & -0.045 & 0.021 & $0.104 *$ & -0.080 \\
\hline \multirow{2}{*}{ edsurname } & $(0.131)$ & $(0.099)$ & $(0.063)$ & $(0.144)$ \\
\hline & 0.062 & 0.030 & $0.021 * * *$ & $-0.113 * *$ \\
\hline \multirow[t]{2}{*}{ ossurname } & $(0.055)$ & $(0.037)$ & $(0.005)$ & $(0.055)$ \\
\hline & $0.404 * * *$ & 0.027 & $-0.026 * * *$ & $-0.406 * * *$ \\
\hline odsurname & $(0.066)$ & $(0.065)$ & $(0.004)$ & $(0.013)$ \\
\hline \multirow{2}{*}{ hexecutive } & 0.013 & $0.075 * *$ & -0.002 & $-0.086 * *$ \\
\hline & $(0.050)$ & $(0.036)$ & $(0.014)$ & $(0.042)$ \\
\hline \multirow{2}{*}{ peduc } & $-0.023 * * *$ & -0.002 & -0.001 & $0.025 * * *$ \\
\hline & $(0.008)$ & $(0.005)$ & $(0.003)$ & $(0.008)$ \\
\hline \multirow{3}{*}{ phouse } & $0.176 * * *$ & -0.034 & 0.003 & $-0.145 * * *$ \\
\hline & $(0.040)$ & $(0.031)$ & $(0.014)$ & $(0.044)$ \\
\hline & -0.002 & 0.002 & 0.001 & -0.001 \\
\hline pincome & $(0.005)$ & $(0.003)$ & $(0.002)$ & $(0.004)$ \\
\hline \multirow{2}{*}{ hretired*pincome } & 0.008 & -0.001 & -0.005 & -0.001 \\
\hline & $(0.008)$ & $(0.005)$ & $(0.004)$ & $(0.008)$ \\
\hline \multirow{2}{*}{ eeduc } & $-0.037 * * *$ & 0.003 & 0.004 & $0.030 * * *$ \\
\hline & $(0.009)$ & $(0.006)$ & $(0.004)$ & $(0.009)$ \\
\hline \multirow{2}{*}{ keduc } & 0.001 & 0.004 & -0.001 & -0.004 \\
\hline & $(0.011)$ & $(0.007)$ & $(0.005)$ & $(0.010)$ \\
\hline \multirow{2}{*}{ psacrifice } & 0.007 & 0.028 & -0.006 & -0.030 \\
\hline & $(0.029)$ & $(0.019)$ & $(0.010)$ & $(0.028)$ \\
\hline \multirow{2}{*}{ pchildduty } & 0.040 & 0.029 & 0.001 & $-0.070 * *$ \\
\hline & $(0.032)$ & $(0.020)$ & $(0.010)$ & $(0.031)$ \\
\hline \multirow{2}{*}{ pesonduty } & $0.061 *$ & $-0.043 * *$ & -0.016 & -0.003 \\
\hline & $(0.031)$ & $(0.021)$ & $(0.010)$ & $(0.030)$ \\
\hline \multirow{2}{*}{ elderson } & 0.075 & 0.053 & -0.078 & -0.050 \\
\hline & $(0.055)$ & $(0.035)$ & $(0.076)$ & $(0.060)$ \\
\hline \multirow{2}{*}{ psingle } & $0.114 * * *$ & $0.065 * *$ & -0.006 & $-0.172 * * *$ \\
\hline & $(0.039)$ & $(0.028)$ & $(0.012)$ & $(0.036)$ \\
\hline \multirow{2}{*}{ edaughter } & 0.011 & 0.025 & -0.002 & -0.034 \\
\hline & $(0.067)$ & $(0.030)$ & $(0.083)$ & $(0.065)$ \\
\hline \multirow{2}{*}{ oson } & 0.038 & -0.001 & -0.013 & -0.024 \\
\hline & $(0.058)$ & $(0.033)$ & $(0.011)$ & $(0.058)$ \\
\hline \multirow{2}{*}{ odaughter } & 0.014 & 0.033 & -0.014 & -0.032 \\
\hline & $(0.048)$ & $(0.038)$ & $(0.010)$ & $(0.043)$ \\
\hline
\end{tabular}

Data source: The same as Table 1.

Notes: The same as Table 2 . 
Table 4: Estimation Results for Sample (iii) (Marginal Effects)

\begin{tabular}{|c|c|c|c|c|}
\hline \multirow[b]{2}{*}{ Dependent variable } & \multicolumn{4}{|c|}{ Sample (iii) (1060 observations) } \\
\hline & $\begin{array}{l}\text { Parents live with } \\
\text { their eldest } \\
\text { daughter }(=1)\end{array}$ & $\begin{array}{l}\text { Parents live with } \\
\text { children other than } \\
\text { their eldest daughter } \\
\qquad(=2)\end{array}$ & $\begin{array}{l}\text { Parents live with } \\
\text { both their eldest } \\
\text { daughter and other } \\
\text { children }(=3)\end{array}$ & $\begin{array}{l}\text { Parents live } \\
\text { independently } \\
\qquad(=4)\end{array}$ \\
\hline & $(\mathrm{x})$ & (xi) & (xii) & (xiii) \\
\hline \multirow{2}{*}{ hselfempl } & -0.001 & 0.016 & 0.011 & -0.026 \\
\hline & $(0.025)$ & $(0.031)$ & $(0.020)$ & $(0.036)$ \\
\hline \multirow{2}{*}{ hprofl } & $-0.179 * * *$ & 0.087 & $0.175 * * *$ & -0.083 \\
\hline & $(0.044)$ & $(0.079)$ & $(0.047)$ & $(0.083)$ \\
\hline \multirow{2}{*}{ essurname } & -0.064 & -0.015 & $-0.080 *$ & 0.159 \\
\hline & $(0.063)$ & $(0.101)$ & $(0.044)$ & $(0.108)$ \\
\hline \multirow{3}{*}{ edsurname } & $0.466 * * *$ & $-0.113 * *$ & $-0.079 *$ & $-0.274 * * *$ \\
\hline & $(0.067)$ & $(0.044)$ & $(0.041)$ & $(0.052)$ \\
\hline & 0.011 & 0.056 & $0.148 * *$ & $-0.215 * *$ \\
\hline \multirow{2}{*}{ ossurname } & $(0.111)$ & $(0.115)$ & $(0.048)$ & $(0.101)$ \\
\hline & 0.029 & $0.120 * *$ & -0.047 & -0.101 \\
\hline odsurname & $(0.045)$ & $(0.058)$ & $(0.065)$ & $(0.063)$ \\
\hline \multirow{2}{*}{ hexecutive } & $0.068 *$ & -0.024 & -0.016 & -0.028 \\
\hline & $(0.035)$ & $(0.042)$ & $(0.031)$ & $(0.047)$ \\
\hline \multirow{2}{*}{ peduc } & 0.000 & 0.000 & $-0.012 * *$ & 0.012 \\
\hline & $(0.006)$ & $(0.007)$ & $(0.005)$ & $(0.008)$ \\
\hline \multirow{2}{*}{ phouse } & 0.040 & $0.076 * *$ & $0.063 * * *$ & $-0.179 * * *$ \\
\hline & $(0.028)$ & $(0.032)$ & $(0.024)$ & $(0.043)$ \\
\hline \multirow{2}{*}{ pincome } & 0.003 & 0.002 & -0.005 & 0.000 \\
\hline & $(0.003)$ & $(0.004)$ & $(0.003)$ & $(0.005)$ \\
\hline \multirow{2}{*}{ hretired*pincome } & -0.002 & 0.002 & 0.007 & -0.008 \\
\hline & $(0.005)$ & $(0.006)$ & $(0.006)$ & $(0.008)$ \\
\hline \multirow{2}{*}{ eeduc } & -0.006 & 0.002 & -0.001 & 0.006 \\
\hline & $(0.006)$ & $(0.008)$ & $(0.006)$ & $(0.010)$ \\
\hline \multirow{2}{*}{ keduc } & -0.004 & $-0.019 * * *$ & $-0.010 * *$ & $0.034 * * *$ \\
\hline & $(0.006)$ & $(0.007)$ & $(0.004)$ & $(0.008)$ \\
\hline \multirow{2}{*}{ psacrifice } & 0.011 & 0.017 & -0.017 & -0.011 \\
\hline & $(0.020)$ & $(0.024)$ & $(0.017)$ & $(0.028)$ \\
\hline \multirow{2}{*}{ pchildduty } & 0.031 & -0.010 & 0.010 & -0.031 \\
\hline & $(0.020)$ & $(0.026)$ & $(0.019)$ & $(0.030)$ \\
\hline \multirow{2}{*}{ pesonduty } & -0.028 & 0.035 & 0.020 & -0.027 \\
\hline & $(0.021)$ & $(0.026)$ & $(0.019)$ & $(0.030)$ \\
\hline \multirow{2}{*}{ elderson } & -0.013 & $-0.307 * * *$ & $0.399 * * *$ & -0.079 \\
\hline & $(0.032)$ & $(0.028)$ & $(0.045)$ & $(0.049)$ \\
\hline \multirow{2}{*}{ psingle } & 0.029 & $0.074 * *$ & $0.069 * * *$ & $-0.172 * * *$ \\
\hline & $(0.027)$ & $(0.033)$ & $(0.024)$ & $(0.037)$ \\
\hline \multirow{2}{*}{ eson } & $-0.080 * *$ & $0.132 * * *$ & 0.012 & -0.065 \\
\hline & $(0.033)$ & $(0.031)$ & $(0.018)$ & $(0.052)$ \\
\hline \multirow[b]{2}{*}{ oson } & -0.010 & $0.103 * *$ & -0.012 & $-0.082 *$ \\
\hline & $(0.027)$ & $(0.042)$ & $(0.018)$ & $(0.043)$ \\
\hline \multirow{2}{*}{ odaughter } & -0.048 & 0.047 & 0.030 & -0.029 \\
\hline & $(0.031)$ & $(0.033)$ & $(0.030)$ & $(0.042)$ \\
\hline
\end{tabular}

Data source: The same as Table 1.

Notes: The same as Table 2 . 
${ }^{1}$ By contrast, Ando, et al. (1986) and Hayashi (1997) find that parental assets lower the probability of coresidence. The conflicting results are presumably due to the presence of two conflicting effects: To the extent that parents value their privacy, they will want to live apart from their children if they can afford to do so, and thus parental wealth will have a negative impact on the probability of coresidence. By contrast, to the extent that greater parental wealth will induce their children to live with them, parental wealth will have a positive impact on the probability of coresidence. The net effect of parental wealth will thus depend on the relative strengths of these two effects.

2 There are some studies for countries other than Japan that analyze living arrangements and caregiving in the case of multiple children (e.g., Hoerger, et al. (1996), Hiedmann and Stern (1999), Checkovich and Stern (2002), Engers and Stern (2002), and Konrad, et al. (2002)). For example, Konrad, et al. (2002) analyze the residential location decisions of children in Germany and find evidence that German children are altruistic toward their parents but that the first-born child exploits his or her first-mover advantage by locating far from his or her parents in order to shift the burden of caring for them to his or her younger siblings.

${ }^{3}$ It is true that dropping respondents with four or more children will lead to sample selection bias, especially since those with four or more children are likely to belong to an earlier cohort and have more traditional values, as pointed out by an anonymous referee, but we do not believe that this bias will be all that serious because we control for the age of parents and because those with four or more children compromise only 5.3 percent of the total sample.

${ }^{4}$ We use the $\operatorname{mfx} 88$ command in STATA to calculate the marginal effect of multinomial logit models.

${ }^{5}$ We did not include ossurname or odsurname in the sample of respondents with only one child for obvious reasons and we did not include essurname in this sample either because there was only one observation for which the value of this variable was one, meaning that its coefficient could not be estimated.

${ }^{6}$ The incomes of the working elderly and the retired elderly will not be directly comparable because the incomes of the working elderly will be higher as a ratio of their lifetime incomes than the incomes of the retired elderly. In order to control for this, we included the cross-product of hretired (a variable that equals one if the father (the mother if there is no father) is retired) and pincome in addition to pincome.

${ }^{7}$ Note, however, that hexecutive, peduc, and pincome are all proxies for parental income, which is not necessarily a bequeathable asset. By contrast, phouse does not suffer from this drawback because housing is almost always bequeathed to one's children in Japan.

${ }^{8}$ However, as Behrman, Pollak, and Taubman (1982) have shown, it is theoretically possible that 
parental preferences will be such that transfers to their children will be reinforcing rather than compensating.

${ }^{9}$ Because of the possibility that there is multicollinearity among the proportions of respondents adhering to the three views, we checked for this possibility and obtained the following results: the correlation between the probability of respondents adhering to views (a) and (b) is 0.195 , that between the probability of respondents adhering to views (a) and (c) is 0.266 , and that between the probability of respondents adhering to views (b) and (c) is 0.384 . Thus, the correlation between the proportions of respondents adhering to views (b) and (c) is the highest, but even this correlation is not overwhelmingly high.

${ }^{10}$ We did not include eson in the sample of respondents with multiple children including at least one son or edaughter in the sample of respondents with multiple children including at least one daughter because they equal one for all observations in these samples. Moreover, we included only eson in the sample of respondents with only one child.

${ }^{11}$ Dekle (1990) reaches the same conclusion (that the Japanese are selfish) by showing that the number of living children does not have a significant impact on the saving behavior of the elderly in Japan, which suggests that they do not have a bequest motive. 